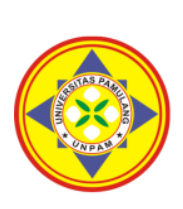

\title{
PENGARUH DISIPLIN KERJA DAN KEPUASAN KERJA TERHADAP TURNOVER INTENTION KARYAWAN PADA PT. CITRA BETAWI DI CILANDAK JAKARTA SELATAN
}

\author{
${ }^{1 *}$ Hafis Laksmana Nuraldy, ${ }^{2}$ Guruh Dwi Pratama, ${ }^{3}$ Muhammad Zaenal Muttaqin Abdi \\ Universitas Pamulang, Tangerang Selatan, Banten, Indonesia \\ *dosen02460@unpam.ac.id
}

\begin{abstract}
Abstrak
Penelitian ini bertujuan untuk mengetahui pengaruh disiplin kerja dan kepuasan kerja terhadap Turnover intention karyawan pada PT. Citra Betawi di Cilandak Jakarta Selatan. Metode yang digunakan adalah explanatory research dengan teknik analisis menggunakan analisis statistik dengan pengujian regresi, korelasi, determinasi dan uji hipotesis. Hasil penelitian ini disiplin kerja berpengaruh signifikan terhadap Turnover intention karyawan sebesar 31,8\%, uji hipotesis diperoleh nilai Sig. 0,000 $<0,05$. Kepuasan kerja berpengaruh signifikan terhadap Turnover intention karyawan sebesar 30,0\%, uji hipotesis diperoleh nilai Sig. 0,000 < 0,05. Disiplin kerja dan kepuasan kerja secara simultan berpengaruh signifikan terhadap Turnover intention karyawan dengan persamaan regresi $Y=47,568$ 0,351X1 - 0,101X2 dan kontribusi pengaruh sebesar 32,0\%, uji hipotesis diperoleh nilai Sig. 0,000<0,05.

Kata Kunci: Disiplin Kerja, Kepuasan Kerja, Turnover Intention Karyawan

\section{Abstract}

This study aims to determine the effect of work discipline and job satisfaction on employee turnover intention at PT. Citra Betawi in Cilandak, South Jakarta. The method used is explanatory research with analytical techniques using statistical analysis with regression, correlation, determination and hypothesis testing. The result of this research is that work discipline has a significant effect on employee turnover intention of $31.8 \%$, the hypothesis test is obtained by the value of Sig. $0.000<0.05$. Job satisfaction has a significant effect on employee turnover intention of $30.0 \%$, hypothesis testing obtained the value of Sig. $0.000<0.05$. Work discipline and job satisfaction simultaneously have a significant effect on employee turnover intention with the regression equation $Y=47.568-0.351 \mathrm{X} 1-0.101 \mathrm{X} 2$ and the contribution of the influence is $32.0 \%$, hypothesis testing is obtained by Sig. $0.000<0.05$.
\end{abstract}

Keywords: Work Discipline, Job Satisfaction, Employee Turnover Intention

\section{PENDAHULUAN}

Dalam perkembangan zaman yang semakin modern, sudah sepatutnya bangsa Indonesia mulai harus berbenah diri agar lebih mampu memperdulikan kualitas sumber daya manusia yang dimilikinya, Sumber daya manusia merupakan suatu aset yang sangat berharga bagi suatu negara. Semakin berkualitas sumber daya manusia yang dimiliki oleh suatu negara, maka akan semakin memungkinkan suatu negara akan menjadi negara yang maju.

Berdasarkan uraian diatas maka manajemen sumber daya manusia sangatlah penting bagi perusahaan dan juga bagi sumber daya manusia itu sendiri. Demi peningkatan sumber daya manusia yang berkualitas serta persiapan dalam mengahadapi persaingan dengan perusahaan lain maka, PT Citra Rasa Betawi semakin berusaha meningkatkan kualitas sumber daya manusia yang dimiliki.

PT Citra Rasa Betawi atau lebih familiarnya adalah Kafe Betawi merupakan perusahaan yang bergerak dibidang Food $\mathcal{E}$ Beverage. Didirikan pada tahun 1992 yang bermula dari kecintaan Owner terhadap kuliner khas betawi, maka terbentuklah suatu hubungan kerjasama antara Owner dengan pedagang kuliner khas betawi. PT Citra Rasa Betawi memutuskan untuk membuka pasar bagi pecinta makanan 
tradisional, khususnya makanan Betawi. Dengan menyajikan beragam makanan dan jajanan khas Betawi dan menjaga tradisi nenek moyang kita dengan tetap menggunakan bahan-bahan alami terbaik dan berkualitas tinggi. Sajian makanan dari Kafe Betawi tidak diragukan lagi dalam hal cita rasa.

PT Citra Rasa Betawi terus berupaya menyajikan dan melayani para pelanggan dengan penuh integritas tinggi. Hingga saat ini PT Citra Rasa Betawi juga memiliki restoran yang sudah tersebar di Jakarta, Bandung, Surabaya, Bali, Makassar, sampai Manado dengan total mencapai 31 outlet dan keseluruhannya berada di bawah naungan Umay Group. Segala macam inovasi dan perubahan selalu dilakukan untuk mempersiapkan persaingan dengan kompetitor yang semakin hari semakin banyak pendatang baru dengan gaya baru.

Menurut Mangkunegara (2013:129), “Disiplin kerja diartikan sebagai pelaksanaan manajemen untuk memperteguh pedoman-pedoman organisasi". Kadang-kadang, perilaku pekerja dalam organisasi menjadi sangat mengganggu sehingga berdampak dengan kinerja yang menurun. Oleh karena itu,

Tabel 1. Absensi Karyawan PT Citra Rasa betawi Area Jakarta Periode Tahun 2016 - 2020

\begin{tabular}{|c|c|c|c|c|c|c|c|}
\hline \multirow{2}{*}{ Tahun } & \multirow{2}{*}{$\begin{array}{c}\text { Jumlah } \\
\text { Karyawan }\end{array}$} & \multirow{2}{*}{$\begin{array}{l}\text { Hari } \\
\text { Kerja }\end{array}$} & \multicolumn{3}{|c|}{ Kondisi } & \multirow{2}{*}{$\begin{array}{l}\text { Jumlah } \\
\text { Absensi }\end{array}$} & \multirow{2}{*}{ Persentase } \\
\hline & & & Terlambat & Ijin & Alpa & & \\
\hline 2016 & 371 & 286 & 87 & 29 & 56 & 172 & $30 \%$ \\
\hline 2017 & 373 & 286 & 98 & 37 & 42 & 177 & $31 \%$ \\
\hline 2018 & 366 & 286 & 88 & 42 & 57 & 187 & $33 \%$ \\
\hline 2019 & 353 & 286 & 93 & 39 & 46 & 178 & $31 \%$ \\
\hline 2020 & 352 & 286 & 102 & 33 & 68 & 203 & $35 \%$ \\
\hline Rata-rata & 364 & 286 & 94 & 36 & 57 & 183 & $32 \%$ \\
\hline
\end{tabular}

Sumber : HRD PT Citra Rasa Betawi, 2020

Berdasarkan data pada tabel di atas, menunjukkan bahwa jumlah absensi kurang baik karyawan PT Citra Rasa Betawi selama 5 tahun terakhir. Tahun 2016 karyawan yang terlambat, ijin dan alpa sebanyak 172 karyawan atau $30 \%$, tahun 2017 mengalami peningkatan menjadi sebanyak 177 Karyawan atau $31 \%$, tahun 2018 mengalami peningkatan mejadi 187 karyawan atau $33 \%$, sementara pada tahun 2019 mengalami penurunan sebanyak 178 karyawan atau $31 \%$, dan pada tahun kedisiplinan sangat diperlukan dalam kondisi seperti itu. Dalam organisasi, masih banyak karyawan yang terlambat, mengabaikan prosedur keselamatan, tidak mengikuti petunjuk yang telah ditentukam atau terlibat masalah dengan rekan kerjanya. Kedisiplinan harus ditegakan dalam suatu organisasi perusahaan, karena tanpa dukungan disiplin karyawan yang baik, maka sulit bagi perusahaan untuk mewujudkan tujuannya. Jadi kedisiplinan adalah kunci keberhasilan perusahaan mencapai tujuan.

Seperti halnya data yang disajikan dibawah ini, data berikut merupakan bentuk nyata bagaimana tidak konsistennya karyawan PT. Citra Rasa Betawi Area Outlet Jakarta untuk menjaga kedisiplinan dalam bekeja. Kedisiplinan dapat dijadikan tolak ukur bagaimana kondisi stabilitas operasional, semakin baik kedisiplinan dijaga oleh setiap karyawan akan semakin baik pula operasional berjalan dengan efektif dan efisien. Data kedisiplinan tersebut dapat dilihat untuk menjadi gambaran bagaimana tingkat kedisiplinan yang terjadi dan disajikan pada tabel dibawah ini. 
kepatuhan jam kerja. Padahal setiap karyawan memiliki target kerja untuk di penuhi. Ketidakhadiran tanpa keterangan (alpa), jumlah keterlambatan, dan ijin merupakan salah satu contoh pelanggaran disiplin yang dilakukan pegawai.

Kepuasan kerja menurut Dadang (2013:15) adalah "Keadaan emosional yang menyenangkan atau tidak menyenangkan terhadap pekerjaan, kepuasan kerja mencerminkan perasaan seseorang terhadap terhadap pekerjaannya". Biasanya tampak dalam sikap positif para karyawan

Tabel 2. Perubahan Status dan Jabatan Karyawan PT Citra Rasa Betawi Periode Tahun 2018 - 2020

\begin{tabular}{|c|c|c|c|c|c|c|}
\hline Tahun & $\begin{array}{c}\text { Jumlah } \\
\text { Karyawan }\end{array}$ & $\begin{array}{c}\text { Jumlah } \\
\text { Karyawan } \\
\text { Tetap }\end{array}$ & $\begin{array}{c}\text { Jumlah } \\
\text { Karyawan } \\
\text { Kontrak }\end{array}$ & $\begin{array}{c}\text { Jumlah } \\
\text { Karyawan } \\
\text { Coba }\end{array}$ & $\begin{array}{c}\text { Jumlah } \\
\text { Karyawan } \\
\text { Promosi }\end{array}$ & $\begin{array}{c}\text { Persentase } \\
\text { Karyawan } \\
\text { Promosi }\end{array}$ \\
\hline 2018 & 373 & 103 & 94 & 176 & 106 & $28 \%$ \\
\hline 2019 & 366 & 98 & 84 & 184 & 102 & $28 \%$ \\
\hline 2020 & 353 & 96 & 85 & 172 & 88 & $25 \%$ \\
\hline
\end{tabular}

Sumber: HRD PT Citra Rasa Betawi, 2020

Berdasarkan data perubahan Status dan Jabatan pada Tabel 2 dapat dilihat bahwa karyawan yang bekerja pada PT Citra Rasa Betawi, banyak yang belum bisa merasakan kesempatan promosi jabatan dan kenaikan pangkat. Dari tahun 2018 sampai dengan 2020 jumlah karyawan yang mendapatkan kesempatan promosi jabatan tidak mencapai angka 50\%. Jika dilihat dari status karyawan, jumlah karyawan yang masih berada di kategori masa percobaan atau probation yang tentunya membuat paradigma karyawan bahwa tidak adanya tingkat kepastian, sementara karyawan yang statusnya kontrak dan tetap juga

Tabel 3. Turn Over Karyawan PT Citra Rasa BetawiArea Jakarta Periode Tahun 2016-2020

\begin{tabular}{|c|c|c|c|c|c|}
\hline Tahun & $\begin{array}{c}\text { Jumlah } \\
\text { Karyawan } \\
\text { Awal Tahun }\end{array}$ & $\begin{array}{c}\text { Jumlah } \\
\text { Karyawan } \\
\text { Masuk }\end{array}$ & $\begin{array}{c}\text { Jumlah } \\
\text { Karyawan } \\
\text { Keluar }\end{array}$ & $\begin{array}{c}\text { Jumlah } \\
\text { Karyawan } \\
\text { Akhir } \\
\text { Tahun }\end{array}$ & Persentase \\
\hline 2016 & 387 & 143 & 143 & 387 & $37,0 \%$ \\
\hline 2017 & 390 & 129 & 146 & 373 & $37,4 \%$ \\
\hline 2018 & 373 & 130 & 137 & 366 & $36,7 \%$ \\
\hline 2019 & 366 & 127 & 136 & 357 & $37,2 \%$ \\
\hline 2020 & 361 & 135 & 135 & 361 & $37,4 \%$ \\
\hline Rata-rata & 375 & 133 & 139 & 370 & $36,9 \%$ \\
\hline
\end{tabular}

Sumber: HRD PT Citra Rasa Betawi, 2020

Berdasarkan data Turnover karyawan pada Tabel 3 terlihat bahwa tingkat turnover karyawan yang terjadi pada setiap terhadap pekerjaan dan segala sesuatu yang dihadapi dilingkungan kerjanya.

Kepuasan kerja dapat diukur dari berapa banyaknya karyawan mendapatkan kesempatan promosi kerja atau naik jabatan, serta banyaknya karyawan yang sudah diangkat menjadi karyawan tetap. Karena dapat diasumsikan bahwa karyawan yang naik jabatan akan mendapatkan kenaikan gaji. Data banyaknya status kerja dan perubahan jabatan karyawan PT. Citra Rasa Betawi dapat dilihat pada data dibawah ini. bukannya semakin bertambah namun justru mengalami pengurangan setiap tahunnya.

Hal tersebut tentunya menjadi pekerjaan rumah yang menjadi tanggung jawab bagi perusahaan, dalam upaya menciptakan kesejahteraan bagi karyawannya agar karyawan merasakan kepuasan kerja seperti yang didambakan. Oleh karena itu, peneliti menduga kepuasan kerja karyawan PT Citra Rasa Betawi akan berpengaruh terhadap Turnover intention karyawan karyawan PT Citra Rasa Betawi. tahunnya. Pada tahun 2016 jumlah persentase karyawan keluar jika dibandingkan dengan jumlah karyawan 
awal tahun adalah sebesar $37 \%$. Pada tahun 2017 mengalami peningkatan sebesar 37,4\%, sementara pada tahun 2018 jumlah karyawan keluar menurun sebesar 36,7\% dari jumlah karyawan awal tahun, Pada tahun 2019 kembali lagi meningkat jumlah karyawan keluar sebesar 37,2\% dari total karyawan pada awal tahun, sampai dengan tahun 2020 jumlah karyawan keluar kembali lagi meningkat sebesar 37,4\%. Hal tersebut sungguh merupakan situasi yang kritis, bagaimana tidak? Jumlah kayawan keluar (resign) selalu meningkat, namun tidak diimbangi dengan jumlah karyawan yang masuk, justru malah kurang dengan tingkat kebutuhan sehingga jumlah karyawan menjadi berkurang. Hal ini tentunya membuat manajemen harus memutar otak untuk menggantikan staff yang resign atau keluar.

Gejala lain timbulnya Turnover intention karyawan karena karyawan merasa tidak puas atas pekerjaannya seperti mudah mengeluh atas pekerjaanya karena tidak mencapai target, rasa ketidakpuasaan yang dirasakan oleh perusahaan dan karyawan karna rendahnya pelanggan dan penghasilan yang didapat karna semakin ketatnya persaingan bisnis pada food and beverage, terbukanya lapangan kerja baru dibidang food and beverage lain, yang memicu karyawan berhenti bekerja. Manajemen PT Citra Rasa Betawi harus mampu menciptakan kesejahteraan bagi karyawannya baik itu yang berada di outlet maupun kantor pusat. Tujuannya untuk mempertahankan dan memperbaiki kondisi fisik dan mental agar produktivitas kerjanya meningkat.

Berdasarkan pada pemaparan di atas, maka penulis tertarik melakukan penelitian dengan judul "Pengaruh Disiplin Kerja Dan Kepuasan Kerja Terhadap Turnover intention karyawan pada PT. Citra Betawi di Cilandak Jakarta Selatan".

\section{TINJAUAN PUSTAKA}

\section{Disiplin Kerja}

Yang dimaksud dengan disiplin Menurut Edy Sutrisno (2016:89) disiplin adalah "Perilaku seseorang yang sesuai dengan peraturan, prosedur kerja yang ada atau disiplin adalah sikap, tingkah laku, dan perbuatan yang sesuai dengan peraturan dari organisasi baik tertulis maupun tidak tertulis." Adapun indikator yang digunakan meliputi: Taat terhadap aturan waktu, taat terhadap peraturan perusahaan, taat terhadap aturan perilaku dalam pekerjaan, taat terhadap peraturan lainnya.

\section{Kepuasan Kerja}

Yang dimaksud dengan kepuasan kerja Menurut Edy Sutrisno (2014:73) "Kepuasan keja menjadi masalah yang cukup menarik dan penting, karena terbukti besar manfaatnya bagi kepentingan individu, industri dan masyarakat". Adapun indikator yang digunakan meliputi: Kedudukan, pangkat, jaminan finansial, mutu pengawasan

\section{Turnover Intention Karyawan}

Dalam penelitian ini yang dijadikan variabel dependen adalah turnover intention yang diartikan Menurut Carolina (2012:9) “Turnover Intention (intensi keluar) adalah keinginan karyawan untuk berhenti dari keanggotaan suatu organisasi atau memutuskan hubungan dengan organisasi." Adapun indikator yang digunakan meliputi: Pikiran untuk berhenti, keinginan meninggalkan, keinginan mencari pekerjaan lain.

\section{METODE}

Populasi dalam penelitian ini berjumlah 78 responden PT. Citra Betawi di Cilandak Jakarta Selatan, sampel dalam penelitian ini berjumlah 78 responden,j penelitian yang dipakai adalah kuantitatif, dimana tujuannya adalah untuk mengetahui pengaruh antara variabel bebas terhadap variabel terikat baik parsial maupun simultan. Dalam menganalisis data digunakan uji instrumen, uji asumsi klasik, regresi, koefisien korelasi, koefisien determinasi dan uji hipotesis. 
HASIL DAN PEMBAHASAN

1. Analisis Deskriptif

Pada pengujian ini digunakan untuk mengetahui skor minimum dan maksimum, mean score dan standar deviasi dari masing-masing variabel. Adapun hasilnya sebagai berikut:

Tabel 4. Hasil Analisis Descriptive Statistics

Descriptive Statistics

\begin{tabular}{|c|c|c|c|c|c|}
\hline & \multicolumn{5}{|c|}{ Descriptive statustics } \\
\hline & $\mathrm{N}$ & Minimum & $\underset{\mathrm{m}}{\operatorname{Maximu}}$ & Mean & $\begin{array}{c}\text { Std. } \\
\text { Deviation }\end{array}$ \\
\hline Disiplin Kerja (X1) & 78 & 16 & 49 & 35.37 & 7.523 \\
\hline Kepuasan Kerja (X2) & 78 & 18 & 50 & 35.74 & 8.101 \\
\hline $\begin{array}{l}\text { Turn Over Intention } \\
\text { Karyawan }(Y)\end{array}$ & 78 & 19 & 45 & 31.53 & 6.055 \\
\hline Valid N (listwise) & 78 & & & & \\
\hline
\end{tabular}

Disiplin kerja diperoleh varians minimum sebesar 32 dan varians maximum 48 dengan mean score sebesar 3,81 dengan standar deviasi 4,019.

Kepuasan kerja diperoleh varians minimum sebesar 30 dan varians maximum 46 dengan mean score sebesar 3,83 dengan standar deviasi 3,664.

Turnover intention karyawan diperoleh varians minimum sebesar 32 dan varians maximum 47 dengan mean score sebesar 3,91 dengan standar deviasi 3,499 .
2. Analisis Verifikatif

Pada analisis ini dimaksudkan untuk mengetahui pengaruh variabel independen terhadap variabel dependen. Adapun hasil pengujian sebagai berikut:

a. Analisis Regresi Linier Berganda

Uji regresi ini dimaksudkan untuk mengetahui perubahan variabel dependen jika variabel independen mengalami perubahan. Adapun hasil pengujiannya sebagai berikut:

Tabel 5. Hasil Pengujian Regresi Linier Berganda

\section{Coefficients}

Unstandardized Coefficients

\begin{tabular}{ll|r|r|r|r|r}
\multicolumn{1}{l}{ Model } & \multicolumn{1}{c}{ B } & Std. Error & Beta & \multicolumn{1}{c}{$\mathrm{t}$} & \multicolumn{1}{c}{ Sig. } \\
\hline \multirow{2}{*}{ (Constant) } & 47.568 & 2.770 & & 17.170 & .000 \\
\cline { 2 - 7 } & Disiplin Kerja (X1) & -.351 & .232 & -.436 & -1.513 & .134 \\
\hline & Kepuasan Kerja (X2) & -.101 & .215 & -.136 & -.471 & .639 \\
\hline
\end{tabular}

a. Dependent Variable: Turn Over Intention Karyawan (Y)

Berdasarkan hasil pengujian pada tabel di atas, diperoleh persamaan regresi $\mathrm{Y}=47,568$ 0,351X1 - 0,101X2. Dari persamaan tersebut dijelaskan sebagai berikut:

1) Konstanta sebesar 47,568 diartikan jika disiplin kerja dan kepuasan kerja tidak ada, maka telah terdapat nilai Turnover intention karyawan sebesar 47,568 point.

2) Koefisien regresi disiplin kerja sebesar -0,351, angka ini negatif artinya setiap ada perubahan disiplin kerja sebesar -0,351 maka Turnover intention karyawan akan mengalami penurunan sebesar 0,351 point.

3) Koefisien regresi kepuasan kerja sebesar -0,101, angka ini negatif artinya setiap ada perubahan kepuasan kerja sebesar -0,101 maka Turnover intention karyawan akan mengalami penurunan sebesar 0,101 point.

\section{b. Analisis Koefisien Korelasi}

Analisis koefisien korelasi dimaksudkan untuk mengetahui tingkt kekuatan hubungan dari variabel independen terhadap 
variabel dependen baik secara parsial maupun simultan. Adapun hasil

pengujian sebagai berikut:

Tabel 6. Hasil Pengujian Koefisien Korelasi Disiplin kerja Terhadap Turnover intention karyawan.

Correlations $^{\mathrm{b}}$

\begin{tabular}{ll|r|r} 
& & $\begin{array}{c}\text { Disiplin Kerja } \\
(\mathrm{X} 1)\end{array}$ & $\begin{array}{l}\text { Turn Over Intention } \\
\text { Karyawan }(\mathrm{Y})\end{array}$ \\
\hline Disiplin Kerja (X1) & Pearson Correlation & 1 & $-.564^{* *}$ \\
\cline { 2 - 4 } & Sig. (2-tailed) & & .000 \\
\hline Turn Over Intention & Pearson Correlation & $-.564^{* *}$ & 1 \\
\cline { 2 - 4 } Karyawan (Y) & Sig. (2-tailed) & .000 & \\
\hline
\end{tabular}

**. Correlation is significant at the 0.01 level (2-tailed).

b. Listwise $\mathrm{N}=78$

Berdasarkan hasil pengujian diperoleh nilai korelasi sebesar $-0,564$ artinya disiplin kerja memiliki

hubungan yang negatif sedang terhadap Turnover intention

Tabel 7. Hasil Pengujian Koefisien Korelasi Kepuasan kerja Terhadap Turnover intention karyawan.

\section{Correlations $^{\mathrm{b}}$}

\begin{tabular}{|c|c|c|c|}
\hline & & $\begin{array}{l}\text { Kepuasan } \\
\text { Kerja }(X 2)\end{array}$ & $\begin{array}{c}\text { Turn Over Intention } \\
\text { Karyawan }(Y)\end{array}$ \\
\hline \multirow[t]{2}{*}{ Kepuasan Kerja (X2) } & Pearson Correlation & 1 & $-.547^{*}$ \\
\hline & Sig. (2-tailed) & & .000 \\
\hline \multirow{2}{*}{$\begin{array}{l}\text { Turn Over Intention } \\
\text { Karyawan }(Y)\end{array}$} & Pearson Correlation & $-.547^{* *}$ & 1 \\
\hline & Sig. (2-tailed) & .000 & \\
\hline
\end{tabular}

Berdasarkan hasil pengujian diperoleh nilai korelasi sebesar $-0,547$ artinya kepuasan kerja memiliki

hubungan yang negatif sedang terhadap Turnover intention karyawan.

Tabel 8. Hasil Pengujian Koefisien Korelasi Disiplin kerja dan Kepuasan kerja secara simultan Terhadap Turnover intention karyawan.

\begin{tabular}{|c|c|c|c|c|}
\hline \multicolumn{5}{|c|}{ Model Summary } \\
\hline Model & $\mathrm{R}$ & R Square & $\begin{array}{l}\text { Adjusted R } \\
\text { Square }\end{array}$ & $\begin{array}{l}\text { Std. Error of the } \\
\text { Estimate }\end{array}$ \\
\hline 1 & $.566^{\mathrm{a}}$ & .320 & .302 & 5.058 \\
\hline
\end{tabular}

a. Predictors: (Constant), Kepuasan Kerja (X2), Disiplin Kerja (X1)

Berdasarkan hasil pengujian diperoleh nilai korelasi sebesar -0,566 artinya disiplin kerja dan kepuasan kerja secara simultan memiliki hubungan yang negatif sedang terhadap Turnover intention karyawan. c. Analisis Koefisien Determinasi

Analisis koefisien determinasi dimaksudkan untuk mengetahui besarnya persentase pengaruh dari variabel independen terhadap variabel dependen baik secara parsial maupun simultan. Adapun hasil pengujian sebagai berikut: 
Tabel 9. Hasil Pengujian Koefisien Determinasi Disiplin kerja Terhadap Turnover intention karyawan.

Model Summary

\begin{tabular}{|c|c|c|c|c|}
\hline \multicolumn{5}{|c|}{ VIouer sumintary } \\
\hline Model & $\mathrm{R}$ & R Square & $\begin{array}{l}\text { Adjusted R } \\
\text { Square }\end{array}$ & $\begin{array}{l}\text { Std. Error of the } \\
\text { Estimate }\end{array}$ \\
\hline 1 & $.564^{\mathrm{a}}$ & .318 & .309 & 5.032 \\
\hline
\end{tabular}

a. Predictors: (Constant), Disiplin Kerja (X1)

Berdasarkan hasil pengujian diperoleh nilai determinasi sebesar 0,318 artinya disiplin kerja memiliki

kontribusi pengaruh sebesar 31,8\% terhadap Turnover intention karyawan.

Tabel 10. Hasil Pengujian Koefisien Determinasi Kepuasan kerja Terhadap Turnover intention karyawan.

Model Summary

\begin{tabular}{|c|c|c|c|c|}
\hline \multicolumn{5}{|c|}{ thenes } \\
\hline Model & $\mathrm{R}$ & R Square & $\begin{array}{l}\text { Adjusted R } \\
\text { Square }\end{array}$ & $\begin{array}{l}\text { Std. Error of the } \\
\text { Estimate }\end{array}$ \\
\hline 1 & $.547^{a}$ & .300 & .290 & 5.101 \\
\hline
\end{tabular}

a. Predictors: (Constant), Kepuasan Kerja (X2)

Berdasarkan hasil pengujian diperoleh nilai determinasi sebesar 0,300 artinya kepuasan kerja memiliki

kontribusi pengaruh sebesar 30,0\% terhadap Turnover intention karyawan.

Tabel 11. Hasil Pengujian Koefisien Determinasi Disiplin kerja dan Kepuasan kerja Terhadap Turnover intention karyawan.

Model Summary

\begin{tabular}{l|c|c|cr} 
& \multicolumn{3}{c}{ Model Summary } \\
Model & $\mathrm{R}$ & R Square & $\begin{array}{c}\text { Adjusted R } \\
\text { Square }\end{array}$ & \multicolumn{2}{c}{$\begin{array}{c}\text { Std. Error of the } \\
\text { Estimate }\end{array}$} \\
\hline 1 & $.566^{\mathrm{a}}$ & .320 & .302 & 5.058 \\
\hline a. Predictors: (Constant), Kepuasan Kerja (X2), Disiplin Kerja (X1)
\end{tabular}

Berdasarkan hasil pengujian diperoleh nilai determinasi sebesar 0,320 artinya disiplin kerja dan kepuasan kerja secara simultan memiliki kontribusi pengaruh sebesar $32,0 \%$ terhadap Turnover intention karyawan, sedangkan sisanya sebesar $68,0 \%$ dipengaruhi faktor lain.

d. Uji Hipotesis

Uji hipotesis Parsial (Uji t)

Pengujian hipotesis dengan uji $t$ digunakan untuk mengetahui hipotesis parsial mana yang diterima. Hipotesis pertama: Terdapat pengaruh yang signifikan antara disiplin kerja terhadap Turnover intention karyawan.

Tabel 12. Hasil Uji Hipotesis Disiplin kerja Terhadap Turnover intention karyawan.

\begin{tabular}{|c|c|c|c|c|c|c|}
\hline & & & efficients ${ }^{a}$ & & & \\
\hline & & $\begin{array}{r}\text { Unstan } \\
\text { Coef }\end{array}$ & $\begin{array}{l}\text { dardized } \\
\text { ficients }\end{array}$ & $\begin{array}{c}\text { Standardize } \\
\mathrm{d} \\
\text { Coefficients }\end{array}$ & & \\
\hline & & B & Std. Error & Beta & $\mathrm{t}$ & Sig. \\
\hline & (Constant) & 47.589 & 2.756 & & 17.269 & .000 \\
\hline & Disiplin Kerja (X1) & -.454 & .076 & -.564 & -5.958 & .000 \\
\hline
\end{tabular}

a. Dependent Variable: Turn Over Intention Karyawan (Y)

Berdasarkan hasil pengujian pada tabel di atas, diperoleh nilai Sig. $0,000<0,05$, dengan demikian hipotesis pertama yang diajukan bahwa terdapat pengaruh yang signifikan atara disiplin kerja terhadap Turnover intention karyawan diterima. 
Tabel 13. Hasil Uji Hipotesis Kepuasan kerja Terhadap Turnover intention karyawan.

\section{Coefficients ${ }^{\mathrm{a}}$}

Unstandardized

Coefficients

\begin{tabular}{|c|c|c|c|c|c|c|}
\hline \multirow{2}{*}{\multicolumn{2}{|c|}{ Model }} & \multicolumn{2}{|c|}{ Coefficients } & \multirow{2}{*}{$\begin{array}{c}\text { Coefficients } \\
\text { Beta }\end{array}$} & \multirow[b]{2}{*}{$\mathrm{t}$} & \multirow[b]{2}{*}{ Sig. } \\
\hline & & B & Std. Error & & & \\
\hline 1 & (Constant) & 46.151 & 2.629 & & 17.553 & .000 \\
\hline & Kepuasan Kerja (X2) & -.409 & .072 & -.547 & -5.702 & .000 \\
\hline
\end{tabular}

a. Dependent Variable: Turn Over Intention Karyawan $(\mathrm{Y})$

Berdasarkan hasil pengujian pada tabel di atas, diperoleh Sig. 0,000 $<0,05$, dengan demikian hipotesis kedua yang diajukan bahwa terdapat pengaruh yang signifikan atara kepuasan kerja terhadap Turnover intention karyawan diterima.

\section{Uji Hipotesis Simultan (Uji F)}

Tabel 14. Hasil Uji Hipotesis Disiplin kerja dan Kepuasan kerja Terhadap Turnover intention karyawan.

ANOVA $^{a}$

\begin{tabular}{|c|c|c|c|c|c|c|}
\hline \multicolumn{2}{|c|}{ Model } & Sum of Squares & $\mathrm{df}$ & Mean Square & $\mathrm{F}$ & Sig. \\
\hline \multirow[t]{3}{*}{1} & Regression & 904.526 & 2 & 452.263 & 17.676 & $.000^{\mathrm{b}}$ \\
\hline & Residual & 1918.923 & 75 & 25.586 & & \\
\hline & Total & 2823.449 & 77 & & & \\
\hline
\end{tabular}

a. Dependent Variable: Turn Over Intention Karyawan (Y)

b. Predictors: (Constant), Kepuasan Kerja (X2), Disiplin Kerja (X1)

Berdasarkan hasil pengujian pada tabel di atas, diperoleh Sig. 0,000 $<0,05$, dengan demikian hipotesis ketiga yang diajukan bahwa terdapat pengaruh yang signifikan atara disiplin kerja dan kepuasan kerja terhadap Turnover intention karyawan diterima.

\section{PEMBAHASAN HASIL PENELITIAN}

1. Pengaruh Disiplin kerja Terhadap Turnover intention karyawan

Disiplin kerja berpengaruh signifikan terhadap Turnover intention karyawan dengan korelasi sebesar -0,564 atau memiliki hubungan yang negatif sedang dengan kontribusi pengaruh sebesar 31,8\%. Pengujian hipotesis diperoleh nilai Sig. 0,000<0,05. Dengan demikian hipotesis pertama yang diajukan bahwa terdapat berpengaruh signifikan antara disiplin kerja terhadap Turnover intention karyawan diterima.

\section{Pengaruh Kepuasan kerja Terhadap Turnover intention karyawan}

Kepuasan kerja berpengaruh signifikan terhadap Turnover intention karyawan dengan korelasi sebesar - 0,547 atau memiliki hubungan yang negatif sedang dengan kontribusi pengaruh sebesar 30,0\%. Pengujian hipotesis diperoleh nilai Sig. 0,000<0,05. Dengan demikian hipotesis kedua yang diajukan bahwa terdapat berpengaruh signifikan antara kepuasan kerja terhadap Turnover intention karyawan diterima.

\section{Pengaruh Disiplin kerja dan Kepuasan kerja Terhadap Turnover intention Karyawan}

Disiplin kerja dan kepuasan kerja berpengaruh signifikan terhadap Turnover intention karyawan dengan diperoleh persamaan regresi $Y=47,568$ 0,351X1 - 0,101X2, nilai korelasi sebesar 0,566 atau memiliki hubungan yang negatif sedang dengan kontribusi 
pengaruh sebesar 32,0\% sedangkan sisanya sebesar $68,0 \%$ dipengaruhi faktor lain. Pengujian hipotesis diperoleh nilai Sig. $0,000<0,05$. Dengan demikian hipotesis ketiga yang diajukan bahwa terdapat berpengaruh signifikan antara disiplin kerja dan kepuasan kerja terhadap Turnover intention karyawan diterima.

\section{PENUTUP}

\section{Kesimpulan}

1. Disiplin kerja berpengaruh signifikan terhadap Turnover intention karyawan dengan kontribusi pengaruh sebesar $31,8 \%$. Uji hipotesis diperoleh nilai Sig. $0,000<0,05$.

2. Kepuasan kerja berpengaruh signifikan terhadap Turnover intention karyawan dengan kontribusi pengaruh sebesar $30,0 \%$. Uji hipotesis diperoleh nilai Sig. $0,000<0,05$.

3. Disiplin kerja dan kepuasan kerja berpengaruh signifikan terhadap Turnover intention karyawan dengan kontribusi pengaruh sebesar 32,0\% sedangkan sisanya sebesar 68,0\% dipengaruhi faktor lain. Uji hipotesis diperoleh nilai Sig. 0,000 < 0,05.

\section{Saran}

1. Perusahaan harus menegakkan peraturan dengan baik sesuai dengan ketentuan yang berlaku guna menjamin karyawan diperlakukan dengan adil.

2. Perusahaan harus selalu memberikan semangat dan apresiasi yang layak untuk memastikan karyawan memiliki semangat kerja yang tinggi.

3. Tingkat turnover karyawan dapat diminimalisir dengan memberdayakan karyawan dengan menegakkan peraturan yang baik dan pemberian kepuasan kerja yang lebih inten lagi.

\section{DAFTAR PUSTAKA}

Abdullah, M (2014) Manajemen dan Evaluasi Kinerja Karyawan, Yogyakarta: Penerbit Aswaja Pressindo.

Affandi, A., Sarwani, A. S., Erlangga, H., Siagian, A. O., Purwanto, A., Effendy,
A. A., ... \& Wahyitno, C. D. M. (2020). Optimization of MSMEs Empowerment in Facing Competition in the Global Market during the COVID-19 Pandemic Time. Systematic Reviews in Pharmacy, 11(11), 1506-1515. Dessler, G. (2006.) Manajemen Sumber Daya Manusia (Jilid II). Jakarta: Indeks.

George Terry R \& Rue, Leslie W. Rue (2016) Dasar-Dasar Manajemen, Jakarta Bumi Aksara.

Gerry Dessler (2016) Human Resources Management, Prenticehall, London: International Inc.

Hasibuan, Malayu S.P. (2016). Manajemen Sumber Daya Manusia. Edisi Revisi. Jakarta: PT Bumi Aksara.

Hermawati, R., Sugiyarti, L., Handayani, R., Sunarsi, D., Alfiah, S., \& Maddinsyah, A. (2020). The Effect of Trilogy Leadership Style and Organization Culture on School Performance: Evidence form Indonesian Senior High School. PalArch's Journal of Archaeology of Egypt/Egyptology, 17(6), 8512-8537.

Imam Ghozali (2017). "Aplikasi Analisis Multivariate Dengan Program SPSS". Edisi Kelima. Semarang: Badan Penerbit Undip.

Istijanto (2014) "Riset Sumber Daya Manusia". Jakarta: PT. Gramedia Pustaka

Luthans Fred (2014) Organizational Behavior, Ney York: McGraw-Hill, New York.

Nurjaya, N., et al. (2021). Pengaruh Kompetensi Sumber Daya Manusia Dan Kemampuan Pemanfaatan Teknologi Terhadap Kinerja Aparatur Desa Pada Kantor Kepala Desa Di Kabupaten Gunungkidul, Yogyakarta. JENIUS (Jurnal Ilmiah Manajemen Sumber Daya Manusia), 4(3), 332-346.

Pawar, A., Sudan, K., Satini, S., \& Sunarsi, D. (2020). Organizational Servant Leadership. International Journal of Educational Administration, Management, and Leadership, 63-76.

Pranoto, P., Jasmani, J., \& Marayasa, I. N. (2019). Pelatihan Digital Marketing 
Untuk Peningkatan Perekonomian Anggota Karang Taruna Al Barkah Di Kampung Cicayur-Tangerang. Jurnal Pengabdian Dharma Laksana, 1(2), 250-258.

Prasada, D., Sunarsi, D., \& Teriyan, A. (2020). Pengaruh Etos Kerja Dan Kompensasi Terhadap Komitmen Organisasi Pada DHL Logistic Di Jakarta. JENIUS (Jurnal Ilmiah Manajemen Sumber Daya Manusia), $4(1), 51-60$.

Robbins, P.S, \& Judge, A.T. (2003). Organizational Behavior. Jakarta: Salemba Empat.

Sugiyono (2017), "Metode Penelitian Administrasi : dilengkapi dengan Metode $R \mathcal{E} D^{\prime \prime}$. Bandung: Alfabeta.

Sunarsi, D. (2017). Pengaruh Kepemimpinan Dan Budaya Organisasi terhadap Kinerja
Karyawan Pada Cabang Pembantu Bank DKI Pondok Labu-Jakarta Selatan. JENIUS, 1(2), 21.

Suryani, N. L., Sularmi, L., Eka, P. D., Sunarsi, D., \& Maddinsyah, A. (2020). The Analysis of Career Development and Placement of Employee Performance in Pt. Global Means of Transindo in Jakarta. Solid State Technology, 63(6), 1382-1389.

Veithzal Rivai (2015) Manajemen Sumber Daya Manusia Untuk Perusahaan, Jakarta: Raja Grafindo Persada.

Wibowo (2015) Manajemen Kinerja, Jakarta: PT. Raja Grafindo Persada

Wilandari, D. F., Sunarsi, D., \& Mas'adi, M. (2021). Pengaruh Penilaian Kerja Terhadap Kinerja Karyawan Pada PT. Jaya Mandiri Rekabuana di Cilandak. Jurnal Ekonomi Efektif, 3(2). 